\title{
Learners' Perceptions towards Online Learning during the Covid-19 Pandemic: A Study at a Center of Foreign Languages in Vietnam
}

\section{Hung Nguyen Quoc Luu}

\author{
Article history \\ Received: 12 September 2021 \\ Accepted: 23 December 2021 \\ Published: 31 December 2021
}

\section{Keywords}

Foreign language center, online learning, perceptions, retention

\author{
Can Tho University, Vietnam \\ Email: Inqhung@ctu.edu.vn
}

\section{INTRODUCTION}

Online learning has experienced rapid growth recently, particularly during school closures because of the Covid19 pandemic for the past few years. According to Allen and Seaman (2013), online learning is one of the fastest growing trends in educational uses of technology. This rapid expansion has prompted educational institutions to increase the number of online classes. However, there have been increasing debates on the effectiveness of online learning in terms of learners' readiness and retention rates of online programs as many learners do not accept the mode of online learning and more learners are also dropping out during online programs (Carr, 2000). At the Center of Foreign Languages in Can Tho University, the pandemic of Covid-19 has forced the institution to implement the policies of online teaching and learning. This study was undertaken with current online learners through an online survey to examine their perceptions of online learning as well as the learner retention rates with online programs.

\section{LITERATURE REVIEW}

\subsection{Online learning readiness}

Readiness for learning, an extremely important factor for any type of learning, is even more significant for online teaching and learning (Cigdem \& Ozturk, 2016). In order to fully reap the benefits of online learning, learners need to be ready. Generally, online learning readiness can be measured in three major features: choices for online learning as opposed to face-to-face instructions, competence in technology, and ability to learn separately (Tang \& Lim, 2013).

With many learners who are more familiar with in-person courses, the transition to online learning can be challenging as in the new online learning environment, learners may feel lonely, without much sense of learning community. Instead of being surrounded by their peers in a classroom, learners generally have to learn remotely and 
independently from home. When learners have the sense of belonging to a learning community, they are more likely to be motivated to complete classwork, feeling safe enough to contribute to discussions, and being open to feedback that can help them improve (Croft et al., 2015).

Technology readiness generally refers to learners' confidence with technical skills of using the Internet and technological tools for online learning. Online learners need basic technical skills to succeed. Some studies (Hung et al., 2010; Wang \& Newlin, 2002) emphasized the role of technology competence in determining learners' achievement in online learning. Learners who enroll in an online course are responsible for having enough computer skills to accomplish the tasks that will be expected of them. From learning how to install and use learning tools such as Zoom or Meet to communicate in chat groups such as Zalo groups, learners can be ready for an online program.

In an online learning environment, many activities are self-directed, where learners need a high level of commitment and can work independently. Since online learning focuses on a more learner-centered environment, learners' motivational beliefs and self-regulatory behaviors would be encouraged to achieve better outcomes (Baeten et al., 2010).

\subsection{Challenges of online learning}

Despite some prominent benefits such as accessibility, affordability and flexibility of online learning, there appear several serious challenges that prevent learners from switching from conventional programs to online learning (Yuzulia, 2021). The common key challenge of learners' acceptance of an online course is Internet connectivity. While Internet has grown in popularity over the past decades, in smaller cities and remote villages, a consistent connection with decent speed is a problem. Without a stable Internet connection for learners or teachers, the learning process is impossible. Lack of online learning facilities is also an obstacle for several disadvantaged learners who hardly accept their online mode of learning. In a statistics report of children's problems in online learning during the Covid-19 period in Vietnam (Statista, 2021), 37.9\% of the young learners encountered technical problems such as Internet interruption, and $9 \%$ of the respondents reported that they had no IT devices for online learning.

New online learning environment is also considered a great challenge for many learners, particularly young learners (Barrot et al., 2021). If in a traditional classroom, learners can learn a lot from being with their peers and teachers, in an online class, there are minimal physical interactions between learners and teachers and among learners. This often results in a sense of isolation for the learners. Self-motivation is also a challenge as online learning requires high level of participation in their learning. As reviewed in online literature, lack of motivation generally is the main reason why many learners fail to complete online courses (Gustiani, 2020).

Although flexibility is usually the main reason for many adult learners to choose online learning, heavy workload and time constraints are usually reasons for class dropouts (Ho \& Ha, 2021). Balancing between work and family and learning can be a serious challenge and these situational barriers generally may negatively affect learners' performance (Baharudin et al., 2013).

\subsection{Retention rates in online classes}

Online learning continues to grow faster than onsite learning, but overall online programs struggle with a lower retention rate (Brown et al., 2013). Online learners tend to withdraw more often, compared to learners in traditional classrooms. Generally, retention rates for online courses have been calculated to be 10 to 20 percent lower than the retention rates for their in-person counterparts in a conventional program. Online literature reviews indicate that the online attrition pattern is not limited to any specific period. Learners may withdraw from online classes anytime during the program or at any level of their learning process.

\section{MATERIALS AND METHODS}

\subsection{Research setting: The Center of Foreign Languages (CFL) and its online programs}

The Center of Foreign Languages, Can Tho University in Vietnam (hereafter referred to as the Center or CFL) has provided varieties of fee-paid courses of foreign languages and began with more online classes during the country's social distancing due to the Covid-19 pandemic. Currently, there are three groups of learners in online programs: One group for exam preparation such as IELTS, TOEIC, or VSTEP, one for General English for adults and the last for General English for young learners. The class size is relatively small, from 15 to 24 learners. The teachers generally use Zoom meetings as a technical tool for their instructions. The course duration is between 8 and 10 weeks, and each class has 2 or 3 Zoom sessions per week.

\subsection{Research design}

In this study, the descriptive survey design was employed, in which questionnaires were distributed to all current online learners of the Center. Questionnaires are considered to be a low-cost research tool that can help to collect 
data from a large number of respondents in a short period of time. A questionnaire based on the literature review of online learning is appropriate in this study because of its feasibility to deliver, respond, and produce reliable data.

\subsection{Participants}

Participants of the study were learners who were attending different English classes at the Center. The three groups of learners including Examination preparation, General English for adults and General English for young learners were checked for learners' attendance during the eight-week program. In the last week of the program, learners were invited to complete an online survey. A total of 164 participants complete the survey. The basic characteristics of the participants are shown in Table 1.

Table 1. Demographic Characteristics of Participants

\begin{tabular}{ccc}
\hline Characteristics & Number & Percentage \\
\hline Gender & & \\
Female & 86 & $52.4 \%$ \\
Male & 78 & $47.6 \%$ \\
\hline Profession & & \\
Student & 140 & $85.4 \%$ \\
Employee & 25 & $14.6 \%$ \\
\hline Types of online course & & \\
Exam preparation & 130 & $79.3 \%$ \\
General English & 34 & $20.7 \%$ \\
\hline
\end{tabular}

\subsection{Instrument}

The learners of the current online courses were invited to complete an online survey. The questionnaire has two sections. The first section requested personal information, and the second section consisted of two open-ended questions, one asking for reasons for class dropouts and another for suggestions for improving online programs.

\subsection{Data collection procedure}

The data of the study were collected in two stages. In the first stage, due to the social distancing during the Covid19 pandemic, all the learners were informed to switch from face-to-face classes to online learning. The information of learners' acceptance of online learning was recorded. In the second stage, the current learners of online courses were checked for their retention and were invited to complete an online survey.

\section{RESULTS AND DISCUSSION}

\subsection{Results}

The results of the study were analyzed from the data of class attendance and the survey of learners' perceptions of online learning.

\subsubsection{Learners' acceptance for online learning}

During the social distancing period in 2021 , the learners of all face-to-face programs were arranged to switch to online learning with zoom meetings with the same schedule. The transitions were mostly voluntary, and the learners decided to have the transition or they could delay their learning. As shown in Table 2, the group of learners studying for examination preparation had the highest level of acceptance with $86.69 \%$ whereas the group of young learners had the lowest level with $50.79 \%$.

Table 2. Learners' Acceptance of Online Learning

\begin{tabular}{lc}
\hline \multicolumn{1}{c}{ Groups of learners } & $\begin{array}{c}\text { Percentage of learners' acceptance } \\
\text { of online learning }\end{array}$ \\
\hline Examination preparation & $215 / 248(86.69 \%)$ \\
\hline General English for adults & $121 / 190(63.68 \%)$ \\
\hline General English for young learners & $767 / 1510(50.79 \%)$ \\
\hline
\end{tabular}

\subsubsection{Reasons for not choosing online learning}

The learners were invited to provide reasons if they could not attend online courses. A number of participants mentioned online learning was not their first choice, and they were reluctant to follow the online program due to the Covid-19 crisis. Some of their comments included:

I don't like online learning as it is very boring. (ST12)

I prefer onsite learning to online learning. (ST64) 
That online learning is not as effective as conventional learning is a common comment shared by many participants who preferred conventional classrooms. Face-to-face learning has been the standard for centuries, so it is natural to assume that online learning cannot compare to it; it is natural that in this study, many people negatively responded to this type of learning.

Another common barrier for online learning is the lack of social interactions, which usually reduces learners' satisfaction (Turley \& Graham, 2019). Online teachers are limited in many instances in encouraging effective teacher-learner and learner-learner interactions. In this study, most participants shared the concern over the lack of interaction as a great challenge for their acceptance of online learning:

There is limited interaction in online learning. (ST06)

I don't like to be with the screen all the time. It is not real learning. I like interactions in classrooms. (ST93)

With young learners, a very popular reason for not choosing online learning is because they do not have the necessary support or assistance when learning at home while many parents are working. In an independent learning environment, without parental involvement, young learners may be more distracted and hardly have good performance.

A concern of accessibility is another reason that has impacted lower-income families as they may not have access to two conditions for successful online learning: high-speed internet service and a computer or a smartphone.

The financial issue is also a reason for several learners who were not satisfied with the transition to online learning. They required a more affordable cost for online programs.

\subsubsection{Retention rates}

The learners who participated in online learning were checked for their attendance during the 8-week course. Overall, the percentage of learner retention of all groups is relatively high (Table 3). The group of young learners had the highest rate of retention of $90.38 \%$. The General English group for adults had the retention rate of $78.68 \%$, and for the exam preparation group, the retention rate is $77.11 \%$. It is relatively natural that the downward trend occurred during the program, particularly with the exam preparation group. However, with the General English group for adults and young children group, there was a slight fluctuation movement.

Table 3. Learner Retention Rates

\begin{tabular}{cccc}
\hline & & (\% of learner attendance) & \\
\hline \multirow{2}{*}{ Week } & $\begin{array}{c}\text { Exam preparation group } \\
\mathbf{N = \mathbf { 2 1 5 }}\end{array}$ & $\begin{array}{c}\text { General English group for adults } \\
\mathbf{N = \mathbf { 1 2 1 }}\end{array}$ & $\begin{array}{c}\text { Young children group } \\
\mathbf{N}=\mathbf{7 6 7}\end{array}$ \\
\hline 1 & 90.76 & 88.24 & 82.79 \\
\hline 2 & 79.23 & 85.29 & 88.66 \\
\hline 3 & 83.08 & 76.47 & 92.31 \\
\hline 4 & 79.23 & 76.47 & 94.78 \\
\hline 5 & 76.92 & 73.53 & 94.26 \\
\hline 6 & 73.08 & 70.59 & 97.59 \\
\hline 7 & 67.69 & 76.47 & 86.70 \\
\hline 8 & 66.92 & 82.35 & 85.91 \\
\hline $\begin{array}{c}\text { Overall } \\
\text { percentage }\end{array}$ & $\mathbf{7 7 . 1 1}$ & $\mathbf{7 8 . 6 8}$ & $\mathbf{9 0 . 3 8}$ \\
\hline
\end{tabular}

\subsubsection{Reasons of dropouts}

While the percentage of learner retention in all online programs was relatively high in this study, the number of dropouts needs further consideration. Sixty one participants (32.2\%) reported that they fully attended the classes; however, over $60 \%$ of the participants indicated different reasons for their absences from some classes during the program. The generally indicated reasons can be classified into some main categories such as time conflict, technical problems, and dissatisfaction with online learning.

The most common reason why the learners (39 participants) could not attend online classes was that they were busy with family or work duties. Also, the participants reported that they could not manage online classes due to the busy schedule of learning at schools or universities. The results are somewhat in line with related literature to online learning, stating that scheduling and time constraints are usually the concerns of online learners (Varre, 2014). Examples of learners' comments in this category included:

I love to study but my work schedule is very unpredictable; usually I cannot manage the time for my class. (ST77) My busy workload stopped my attending class on time and I had to cancel several classes. (ST11) 
My exam schedule in my college was at the same time with my online class. (ST109)

Some participants also reported health problems as a reason for their absence from some online classes although learners' illness can be a common reason for class dropout for both onsite and online courses.

Other common reasons for learner dropouts are problems with Internet connection and electricity supply. Seventeen participants reported that their online classes were interrupted or canceled due to unstable Internet connections in their areas. Some participants reported:

My Internet connection is very weak. It is a nuisance to stay connected and study. (ST41)

My learning is not effective because the wifi usually goes down. (ST63)

I had to reconnect zoom twice or more during the class session due to unstable Internet. Sometimes I could not stay for my study. (ST85)

The power supply was also a reported issue in this study when five participants shared this problem.

It is not very common, but during this course I had to stop my class two times due to the power supply. (ST37)

The online format of the course was challenging for many learners in this study. Several participants had issues relating to online technology such as being confused by the Zoom access or online directions. Some common comments were:

I hardly followed the course at the beginning due to many technical issues. (ST9)

The course should have better guideline and orientation for some learners without good background of technology. (ST29)

Another direct cause for class dropout is due to learner dissatisfaction with online learning. Although not many participants reported this reason (13 out 164 participants), this problem needs further consideration to improve learner retention.

Online learning is boring. (ST16)

I am not comfortable with online learning. I prefer traditional classrooms. (ST110)

Online learning is not my choice. I had no choice due to the Covid-19 pandemic. (ST38)

4.1.5. Suggestions for improving online classes

Participants were also invited to suggest solutions for improving online courses. It is interesting to note that over half of the participants $(61.6 \%)$ confirmed their satisfaction with the program and had no specific suggestions. Most responses were about teachers and their pedagogy, course contents and online materials, the class schedules, technology support, and online course directions.

Online teachers have an essential role in helping prevent learner attrition by creating a comfortable online learning environment where learners can build community and establish trust (Yengin et al., 2010). In this study, eight participants had suggestions directly related to online teachers' roles. Their comments included:

Teacher should be more helpful to facilitate learners with basic knowledge. (ST8)

Teachers need to be friendly and sharing. (ST156)

Regarding teaching techniques or methods, several participants suggested having a better interaction between teachers and learners and also among learners. Learning outcomes need to be informative, and instant and continuous feedback is encouraged. Assessments should also be measurable and realistic in the online setting. Some participants shared their views:

I like my teachers to have more interactive activities. (ST49)

Teachers should provide instant feedback. (ST158)

The lesson objectives need to be informed and reviewed in every lesson. (ST14)

Another common theme for improving the program was the importance of course content in online courses. The teaching content should align with the learning outcomes and assessment strategies. The course should equip learners with sufficient vocabulary and develop language skills of listening, speaking, reading and writing. Some comments included:

The content should be practical. (ST3)

During the course, I need to enhance language skills, especially listening and speaking. (ST92)

I like to have more vocabulary exercises in this course. (ST108)

Online learning materials can be accessed through different kinds such as texts, images, sounds, videos. With online learning, the material should be designed to engage learners with more practical activities. A number of participants indicated that their learning would be better with more practical learning resources. Most participants would like to have more self-learning materials, particularly on the E-learning system. Some of them said:

The online classes needed more interactive activities. (ST58)

The course would be more practical if there were more self-learning exercises. (ST62) 
The class schedule or course duration is also a concern among some participants. Although they were overall satisfied with the program, several participants suggested extending the course length for further practice.

I prefer to have more time for this online course as Ifeel the course duration was somewhat limited.

The lesson sessions should be shorter for more concentration but the course length should be extended.

Another theme of suggestions reported by numerous participants is related to technical and online learning supports. As online classes are vastly different to in-person learning, learners must understand what to expect when they participate in a virtual classroom. Confusion can result in learning cancellation whereas clarity generally can foster learner engagement (Redmond et al., 2018). In a similar vein, in this study, the participants suggested:

The program should provide more technical supports through Zalo groups. (ST163)

I would like to have detailed information of course requirements. (ST72)

\subsection{Discussion}

Online courses are a revolutionary trend of educational technology today, particularly in the process of teaching and learning during the Covid-19 pandemic. From the results of the study, it is assumed that learners' readiness and retention are important conditions and significant indicators of successful online programs.

In line with previous research (Ngampornchai \& Adams, 2016), typical challenges such as lack of Internet connectivity and IT facilities, lack of social interactions as well as the perceived effectiveness of online learning can affect learners' readiness to accept the new mode of learning. In this study, the level of acceptance of online learning varies between the three groups of learners. Adult learners are more self-disciplined and self-regulated, which are important characteristics for online learning (Cercone, 2008). Strong motivation is also a possible explanation for the highest level of acceptance for online learning of the examination preparation group. Additionally, an online learning environment, usually isolated and without physical interactions, seems a great challenge for young learners. The results are relatively in line with a study of Chinese parents' common beliefs, attitudes and concerns related to young children's online learning (Dong et al., 2020).

A very important finding in this study showed that learners' retention rates are positively high in all the groups of learners, particularly with the group of young learners. It is possible that those children who accepted to learn online could be supported by family members to follow and complete the course successfully. However, this explanation of retaining factors needs further investigation.

The study also examined suggestions for improving online learning. In line with online literature (Heng \& Sol, 2020), there are various suggestions to address problems associated with online learning including teachers, course content, online facilities, and at-all-time supports. Generally, improving the quality of online programs requires collaboration to address. Program administrators, teachers, and learner support staff should work together to ensure the success of this growing population of learners. An institution in which functional units combine efforts to support online learners will guarantee its success.

\section{CONCLUSION}

Online learning is one of the dominant alternatives to learning during the Covid-19 pandemic in the new normal period. The results of this study show that most of the learners, especially young learners still preferred traditional face-to-face learning to online learning because of some problems they experienced while doing online learning, such as lack of facilities and necessary interactions. However, the retention rates are relatively high, indicating the perceived quality of online programs at the Center. Online learning is here and is highly likely to stay and continue to excel. The transition from traditional face-to-face classrooms to online learning can be successfully achieved and quality can be ensured if challenges and measures to improve online learning can be closely examined.

Conflict of Interest: No potential conflict of interest relevant to this article was reported.

Funding: The authors received no financial support for this article.

\section{REFERENCES}

Allen, I. E., \& Seaman, J. (2013). Changing course: Ten years of tracking online education in the United States. http://www.onlinelearningsurvey.com/reports/changingcourse.pdf

Baeten, M., Kyndt, E., Struyven, K., \& Dochy, F. (2010). Using student-centred learning environments to stimulate deep approaches to learning: Factors encouraging or discouraging their effectiveness. Educational Research Review, 5(3), 243-260. https://doi.org/10.1016/j.edurev.2010.06.001 
Baharudin, S., Murad, M., \& Mat, N. (2013). Challenges of Adult Learners: A Case Study of Full Time Postgraduates Students. Procedia - Social and Behavioral Sciences, 90(1), 772-781.

Barrot, J. S., Llenares, I. I., \& del Rosario, L. S. (2021). Students' online learning challenges during the pandemic and how they cope with them: The case of the Philippines. Educ Inf Technol. https://doi.org/10.1007/s10639021-10589-X

Brown, M., Keppell, M., Hughes, H., Hard, N., \& Smith, L. (2013). Exploring the disconnections: Student interaction with support services upon commencement of distance education. The International Journal of the First Year in Higher Education, 4(2), 63-74. https://doi.org/ 10.5204/intjfyhe.v4i2.171

Carr, S. (2000). As distance education comes of age, the challenge is keeping the students. Chronicle of Higher Education, 46(23), 39-41.

Cercone, K. (2008). Characteristics of adult learners with implications for online learning design. AACE Journal, 16(2), 137-159.

Cigdem, H., \& Ozturk, M. (2016). Critical components of online learning readiness and their relationships with learner achievement. Turkish Online Journal of Distance Education, 17(2), 98-109.

Croft, N., Dalton, A., \& Grant, M. (2015). Overcoming isolation in distance learning: Building a learning community through time and space. Journal for Education in the Built Environment, 5(1), 27-64. https://doi.org/10.11120/ jebe.2010.05010027

Dong, C., Cao, S., \& Li, H. (2020). Young children's online learning during COVID-19 pandemic: Chinese parents' beliefs and attitudes. Child Youth Serv Rev, 118(1). https://doi.org/10.1016/j.childyouth.2020.105440

Gustiani, S. (2020). Students' motivation in online learning during covid-19 pandemic era: A case study. Holistics Journal, 12(2), 23-40.

Heng, K., \& Sol, K. (2020). Online learning during COVID-19: Key challenges and suggestions to enhance effectiveness. Cambodian Educational Forum. https://www.researchgate.net/publication/346719308_Online_ learning_during_COVID-19_Key_challenges_and_suggestions_to_enhance_effectiveness

Ho, N. Q., \& Ha, M. T. (2021). The challenges and opportunities of online learning during the Covid-19 pandemic. HCMCOUJS-Social Sciences, 11(1), 3-14. https://doi.org/10.46223/HCMCOUJS

Hung, M., Chou, C., Chen, C., \& Own, Z. (2010). Learner readiness for online learning: Scale development and student perceptions. Computers \& Education, 55(1), 1080-1090.

Ngampornchai, A., \& Adams, J. (2016). Students' acceptance and readiness for E-learning in Northeastern Thailand. Int J Educ Technol High Educ, 13(34). https://doi.org/10.1186/s41239-016-0034-x

Online Statistics (2021). Online learning statistics in 2021. https://www.guru99.com/online-learning-statistics.html

Redmond, P., Hefferman, A., Abawi, L., Brown, A., \& Henderson, R. (2018). An online engagement framework for higher education. Online Learning, 22(1), 183-204. https://doi.org/10.24059/olj.v22i1.1175

Statista (2021). Online learning problems faced by children during the COVID-19 pandemic in Vietnam as of April 2020. https://www.statista.com/statistics/1 190894/vietnam-online-learning-problems-for-children-during-covid19-pandemic/

Tang, S. F. \& Lim, C. L. (2013). Undergraduate students' readiness in e-learning: a study at the business school in a Malaysian private university. International Journal of Management \& Information Technology, 4(2), $198-204$.

Turley, C., \& Graham, C. (2019). Interaction, student satisfaction, and teacher time investment in online high school courses. Journal of Online Research, 5(2), 169-198.

Varre, C., Irvin, M. J., Jordan, A. W., Hannum, W. H., \& Farmer, T. W. (2014). Reasons for student dropout in an online course in a rural K-12 setting. Distance Education, 35(3), 324-344. https://files.eric.ed.gov/fulltext/EJ1044355.pdf

Wang, A.T. \& Newlin, M.H. (2002). Online lectures: Benefits for the virtual classroom. THE Journal, 29(1), 17-22.

Yengin, I., Karahoca, D., Karahoca, A., \& Yucel, A. (2010). Roles of teachers in e-learning: How to engage students $\&$ how to get free-elearning and the future. Social and Behavioral Sciences, 2(2), 5775-5787. https://doi.org/ 10.1016/j.sbspro.2010.03.942

Yuzulia, I. (2021). The challenges of online learning during pandemic: Students' voice. Wanastra: Jurnal Bahasa dan Sastra, 13(1), 8-12. https://doi.org/10.31294/w.v12i1 